\title{
Lost in transaction? The transfer effect of strategic consistency
}

\author{
Kerstin Fehre $^{1}$ - Daniel Kronenwett ${ }^{1}$ • \\ Hagen Lindstädt ${ }^{1} \cdot$ Michael Wolff $^{2}$
}

Received: 8 March 2014/Accepted: 9 September 2015/Published online: 21 September 2015

(C) The Author(s) 2015. This article is published with open access at Springerlink.com

\begin{abstract}
Prior empirical studies provide evidence that the learning-curve perspective from manufacturing settings is not directly applicable to strategic management settings. In the latter case learning relates to the quality rather than to the quantity of experience. Regarding the antecedents of organizational learning especially, there are still unanswered questions remaining; for example, the questions what kind of experience has a positive effect on performance and what kind of experience is more of a hindrance than a help. This becomes obvious when looking at acquisitions as examples of strategic management decisions. Results of prior empirical studies analyzing the relationship of acquisition experience and acquisition performance have been mixed. By introducing the concept of strategic consistency, we intend to facilitate a better understanding of the kind of experience necessary for organizational learning. Therefore, we measure the concordance and frequency of change in strategic actions. Employing a sample of 379 acquisition series, we find evidence for a positive transfer effect of strategic consistency within series and, therefore, a positive relationship between strategic consistency and acquisition performance.
\end{abstract}

Kerstin Fehre

kerstin.fehre@kit.edu

Daniel Kronenwett

daniel.kronenwett@kit.edu

Hagen Lindstädt

hagen.lindstaedt@kit.edu

Michael Wolff

michael.wolff@wiwi.uni-goettingen.de

1 Institute of Management, Karlsruhe Institute of Technology (KIT), P.O. Box 6980, 76128

Karlsruhe, Germany

2 Chair of Management and Control, Georg-August-University Goettingen, Platz der Göttinger Sieben 3, Oeconomicum, 37073 Goettingen, Germany 
Keywords Transfer effects - Acquisition series - Strategic consistency · Organizational learning

\section{Introduction}

Acquisitions are important strategic management decisions leading to considerable organizational changes (Barkema and Schijven 2008a; Cording et al. 2008; Ellis et al. 2009). Acquisitions are complex transactions; they consume financial and managerial resources going far beyond everyday business, in terms of both the transaction itself and successive integration. Intuitively, one would expect that acquirers with more transactions experience would better manage the challenges coming along with acquisitions and, therefore, obtain a higher performance than inexperienced acquirers. However, prior empirical studies analyzing the relationship between acquisition experience and acquisition performance have been mixed, ranging from positive (Barkema et al. 1996) via U-shaped (Haleblian and Finkelstein 1999) and inverted U-shaped (Hayward 2002) to negative results (Uhlenbruck et al. 2006) (see Barkema and Schijven 2008b; as well as Ellis et al. 2011 for an overview). As postulated by several researchers (e.g. Barkema and Schijven 2008b; Ellis et al. 2011), these mixed results indicate that "researchers need to dig deeper" (Barkema and Schijven 2008b: 595).

Prior empirical studies analyzing the performance effects of serial acquisitions generally pursue two variant key topics: the effect of time or more specifically acquisition patterns (Klarner and Raisch 2013; Laamanen and Keil 2008; Shi and Prescott 2011, 2012; see Shi et al. 2012 for an overview) and the role of experience on learning effects (Ellis et al. 2011; Finkelstein and Haleblian 2002; Haleblian and Finkelstein 1999; Hayward 2002; Meschi and Métais 2013; Vermeulen and Barkema 2001; see Barkema and Schijven 2008b for an overview). We interconnect these two perspectives by introducing the concept of strategic consistency, which we define in this paper as the coherence of strategic directions of acquisitions within a series. The concept of strategic consistency offers us the possibility to analyze the effect of prior experience gained by earlier-executed transactions of a similar kind. Further, in order to analyze strategic consistency within an acquisition program, the chronological order - and therefore a temporal perspective- has to be taken into consideration. In doing so, we aim to develop further important insights on both the theoretical and practical levels of organizational learning in strategic management settings.

The concept of strategic consistency has always played an essential role in strategic management research (Lamberg et al. 2009). Prior research has shown evidence for a positive impact of strategic consistency on firm performance, especially by avoiding conflicts between multiple strategic goals or multiple measures to realize a certain strategic advantage (Lamberg et al. 2009; Milgrom and Roberts 1990, 1992; Porter 1980, 1996; Robinson et al. 1988). Further, several studies (Milgrom and Roberts 1992; Prahalad and Bettis 1986; Rumelt 1980) attribute strategic consistency to the mechanisms of cognitive patterns and shared cognitive schemes. In this view, they adjudge strategic consistency to be a coordination function in complex strategic management settings, as well as the 
opportunity to deal with imperfect information. Hence, we find indications for a positive effect of strategic consistency on organizational learning effects. In contrast to the high number of theoretical concepts related to strategic consistency, empirical research in this context seems to be underrepresented, with most studies focusing on explorative case studies (Lamberg et al. 2009; Richter and Schmidt 2005; Siggelkow 2002), and to our knowledge strategic consistency has never been empirically tested in the context of acquisition series.

Based on a large sample of 379 series consisting of 1990 European serial transactions, we will empirically analyze the effect of strategic consistency in acquisition series. We intend to supply an answer to the research question as to whether experience in terms of strategic consistency has a positive influence on organizational learning effects and, therefore, performance, respectively. According to Barkema and Schijven (2008b: 596), we define organizational learning as "the transfer of an organization's experience from one event to a subsequent one".

By responding to recent calls in this field to further incorporate a serial perspective into the acquisition stream of research (e.g. Laamanen and Keil 2008; Shi et al. 2012), our intended research contribution of the present study is threefold: First, we contribute to an improved understanding of organization experience and organization learning by analyzing the transfer effect of strategic consistency. Second, the study provides an expansion to empirical research on strategic consistency by analyzing strategic management decisions that are externally clearly detectable based on a large-scale sample. Third, our study proposes managerial implications with respect to an improved development of acquisition capabilities.

The remainder of the paper is organized as follows: In the next section, we introduce the underlying theoretical concept before deriving hypotheses. The third section covers our empirical study, especially descriptions of the sample analyzed, statistical methods applied, and variables measured. Our empirical results are presented in the fourth section. The final section provides a discussion of our findings and outlines directions for future research.

\section{Theory and hypothesis}

Hereinafter, we introduce transfer theory as our theoretical framework. We outline its applicability on organizational level, particularly in the context of M\&A series. Next, we define our conceptualization of strategic consistency and reason why we expect positive effects from a transfer theoretical perspective.

\subsection{Transfer effects}

The basic idea that experience leads to higher performance originates from learningcurve theory, which is applicable to manufacturing settings (e.g. Yelle 1979). However, diverse empirical research studies have shown that the principle of learning-curve theory cannot be transferred one-to-one to complex strategic management settings (Ellis et al. 2011; Finkelstein and Haleblian 2002; Haleblian and Finkelstein 1999; Hayward 2002; Zollo 2009; see Barkema and Schijven 2008b 
for an overview of research on organizational learning in acquisition settings). The results of prior empirical studies show evidence that in strategic management settings, as against manufacturing settings, learning relates to the quality rather than to the quantity of experience (Hayward 2002). Yet, questions with respect to the quality of experience, or, in other words, what kind of experience has a positive effect on performance and what kind of experience is more of a hindrance than a help, are still not completely answered (Barkema and Schijven 2008b). In order to answer these questions, prior research studies have analyzed the transfer effects of organizational learning (e.g. Ellis et al. 2011; Finkelstein and Haleblian 2002).

Transfer theory originates in psychology and educational theory and considers the transfer of knowledge attained by learning in prior settings to subsequent, similar situations. In order to distinguish this from knowledge transfer, Ellis et al. (2011: 1261) stress that "[t]ransfer theory concerns intraperson (or intragroup or intraorganizational) transfer of practices and routines." Thorndike and Woodworth (1901) originated the theory of identical elements, implying that the transfer of learning depends on the proportion to which the learning situation and the new situation have similar characteristics. If the conditions of the learning situation and the subsequent situation are similar, generalization — which means the application of experienceleads to positive transfer effects and, thus, positive outcomes (Finkelstein and Haleblian 2002; Haleblian and Finkelstein 1999; Hearst and Koresko 1968). If conditions are dissimilar, generalization leads to negative transfer effects. This might be the case especially when situations are at first glance recognized as similar, but are structurally different (Finkelstein and Haleblian 2002; Haleblian and Finkelstein 1999; Novick 1988). Discrimination of experience-which means the non-application of experience-normally leads to neutral or no transfer effects. In the case of dissimilar conditions, this is the correct behavior, but in the case of similar conditions, this behavior is inappropriate; it may lead to the repetition of prior mistakes (Haleblian and Finkelstein 1999) or at least be inefficient. Therefore, the similarity and dissimilarity of prior and focal situations is crucial for transfer effects.

Finkelstein and Haleblian (2002) explicitly examine whether transfer effects occur at both, the individual and organizational level. They draw upon the individual level theory, which describes the way in which the experience of one situation affects another, in order to predict parallel organizational outcomes from one situation to another. Organizational experience is integral to their study. Organizations have memories, which differ from the memories of the individuals belonging to the organizations (Walsh 1995). Although organizational memory and individual memory are different, Walsh and Ungson (1991) reason that both types of memory have the same function in terms of information processing. Organizational knowledge is gained from experiences in three stages: information acquisition, retention of experience, and retrieval of experience (Levitt and March 1988; Walsh and Ungson 1991; Meschi and Métais 2013). In several domains of organizational and strategic management research, studies build on transfer theory and foster its applicability on organizational level. For example, in the strategic alliance context, Zollo et al. (2002) examine the effect of accumulated expertise from previous alliances in same technological areas on the performance of the focal alliance. Nadolska and Barkema (2007) study three different sources of learning for 
internationalizing companies, namely experience with international acquisitions, with domestic acquisitions, and with international joint ventures. Piaskowska et al. (2014) focus on differences between diverse forms of joint ventures in order to analyze transfer effects of prior joint venture experience on ex-ante and ex-post performance of subsequent joint ventures. Hutzschenreuter et al. (2014) extend the similarity perspective of acquisition characteristics by analyzing the impact of the degree of mindfulness in the knowledge transfer process. In their literature review, Barkema and Schijven (2008b) identify the research work of Haleblian and Finkelstein (1999) respectively Finkelstein and Haleblian (2002) as starting point for further research studies analyzing experience transfer in acquisition settings (for further literature reviews on research studies analyzing the role of acquisition experience see e.g. Haleblian et al. 2009, Hutzschenreuter et al. 2012).

Finkelstein and Haleblian (2002) examine transfer effects in acquisitions and analyze the effect of similarity between acquirer and targets as well as the similarity between targets of a serial acquirer on acquisition performance. They define similarity as belonging to the same industrial environment based on a Standard Industrial Code (SIC) comparison. The logic behind this choice is based on the assumption that similar industrial environments allow for positive transfer of management practices, routines, and knowledge. They find a positive and significant coefficient for acquirer-to-target similarity, showing evidence for positive transfer effects in the case of similar industry belongings of acquirer and target. Further, in line with the expectation for negative transfer in the case of dissimilar targets in serial acquisitions, they find a negative and significant coefficient in the subsample of dissimilar acquisitions. Their findings correspond previous psychology-based transfer research. They conclude that positive and negative transfer outcomes are found at the organizational level. Interestingly, they do not find support for the hypothesis of the second acquisition outperforming the first acquisition, when both targets belong to the same industry. This result can be interpreted as a signal that similarity of acquisitions refers to more than a shared industrial environment. Alike, Hayward (2002) finds evidence for an inverted U-relationship between the similarity of targets in respect of industry belonging and acquisition performance, i.e. experience from targets that are not highly similar or dissimilar to the focal acquisition increases acquisition performance.

Ellis et al. (2011) seize on the transfer theory and extend the analysis to sizespecific experience. Here, similarity is analyzed in terms of target size. They support their argumentation among others with the thesis that large acquisitions-as they are more complex - require other integration capabilities and processes as well as more managerial capacities than small ones (Shrivastava 1986). Simply applying the knowledge gained and evolved routines when doing small acquisitions to large acquisitions would lead to inappropriate generalization and, therefore, negative transfer effects. They find strong support for their hypothesis that prior small related acquisitions will generate negative transfer effects in the context of a subsequent large related deal. Further, they find only partial support for positive transfer effects from prior experience in large related acquisitions to a subsequent large related acquisition.

Interestingly, both studies-from Finkelstein and Haleblian (2002) as well as from Ellis et al. (2011)_find strong support for negative transfer effects in the case 
of dissimilarities, but find only partial or no support for positive transfer effects in the case of similarities in the principal characteristics analyzed. This can be interpreted as a signal that in the case of existence of at least one main characteristic of the two situations being different, experience is misapplied and generalization is inappropriate. Whereas in the case of similarity between the main characteristics analyzed, it cannot be ruled out that there are other important characteristics not taken into consideration for being different (see Finkelstein and Haleblian 2002 for an overview of possible dissimilarities between targets, as well as Hutzschenreuter et al. 2012 for propositions regarding further transaction content and process characteristics worthwhile to be analyzed in terms of similarity and their effect on the outcome of serial acquisitions). By analyzing the similarity of one main characteristic, it could still be the case that the past and current situations are superficially similar, but structurally different. We assume that the similarity of two complex strategic management decisions-as acquisitions-is not limited to the main characteristics of the targets, like size and a shared industrial environment.

For example, when looking at the integration process, prior experience with respect to industry belonging and target size are indubitably helpful. Nevertheless, we assume that - especially during the integration process-experience with respect to the kind of transaction is also of importance. According to Shrivastava (1986), the need for integration is determined among others by the motives and objectives of the acquisition. Integrating a horizontal acquisition needs knowledge, routines, and processes different from integrating a vertical or lateral acquisition. A horizontal acquisition requires an integration process at nearly every step of the value chain with respect to procedural integration, i.e. integrating systems and procedures on operating and administrative levels, physical integration like the consolidation of production plants and technologies as well as intense managerial integration. Vertical integration often requires only partial integration and only directly adjoining steps of the value chain are affected. In the case of a lateral acquisition pursued in order to gain entry to a new market, the need for integration might be less extensive than in the case of a horizontal acquisition pursued in order to get access to new resources, products, and managerial expertise. Integration is crucial for the success of acquisitions. As several research studies have revealed, a lack of or faulty integration leads to failure of acquisition (Barkema and Schijven 2008a; Cording et al. 2008; Ellis et al. 2011; Ellis et al. 2009; Shrivastava 1986); for instance, because the envisaged synergy effects could not be raised.

Thus, we find evidence that it is not sufficient to analyze whether targets belong to the same industry. It should also be taken into consideration whether transactions are similar in kind of acquisition direction. For example, several targets could be active in the same industry, but on different levels of the value chain. When analyzing the targets from an industry perspective (e.g. based on SIC comparison), one could conclude a high similarity of these acquisitions. From an acquisition direction perspective, they might differ: acquisitions on the same level of the value chain as the acquirer would be rated as horizontal acquisitions, whereas acquisitions on different levels of the value chain-e.g. an acquirer's supplier-would be vertical. When inferring experience from one acquisition and transferring it to the next, relying on similarity solely based on industry perspective may lead to negative 
transfer effects, as the transactions are superficially similar (same industry), but structurally different (different acquisition direction).

Ideally, the strategic direction of an acquisition represents the intended strategy. However, a strategy is not manifested in one single action or decision; according to Mintzberg (1978: 935) strategy is defined as "a pattern in a stream of decisions". So far, studies analyzing the effects of similarities between targets have not taken into account the chronology of the series. The measurement of target similarity is based on the percentage of similar targets within a series. Take for example a series consisting of three similar and two dissimilar targets. When calculating the target similarity, there is no distinction, whether the similar targets were the first acquisitions of a series or the last. From a transfer theoretical perspective, the chronology of a series might play an important role, due to two aspects: forgetting and retrieval of experience. On the one hand, decay and disuse of organizational memory leads to organizational forgetting. That means that stored information is not available to the organization any longer, for example due to lost or destroyed files or individuals leaving the firm. Disuse is caused by the absence of information recall over a longer time period (Meschi and Métais 2013). Decay and disuse are both functions of time. The longer the time period between two similar events, the higher the probability that the relevant experience made in a previous acquisition can not be transferred to the focal acquisition. Discrimination of experience occurs, leading to neutral or no transfer effects. On the other hand, retrieval of information depends on the availability of organizational memory, which is associated with the recency of its use (Levitt and March 1985). The other way round, organizations-like individuals - tend to recall information from the recent past, rather than from older situations. If the prior situation is dissimilar, negative transfer effects may occur. In both cases, retrieval and forgetting of organizational memory, it is assumed to make a difference, in which chronological order the three similar transactions from the example above occur.

So, on one side, there are indications that the strategic acquisition direction might be an important characteristic of acquisitions when analyzing transfer effects. On the other side, the chronology of transactions might be of relevance as well. This is a matter of strategic consistency.

\subsection{Strategic consistency}

The concept of strategic consistency is a fundamental subject already found in classic works on strategy (Miles and Snow 1978; Porter 1980). Most studies adjudge that strategic consistency has a positive effect on corporate success with respect to performance. To name but a few, according to Porter (1996), strategic consistency refers to a distinct, clear competitive strategy, competitive advantages and higher profitability. Robinson et al. (1988) show a positive coherence between strategic consistency of strategic actions for the purpose of the defined strategy, professionalism of the strategic planning process and corporate success.

Whatever definition of strategy one chooses to employ, it is undisputed that a corporate strategy provides direction and serves as a rule for strategic decision making. These main mechanisms of strategy are, for example, clearly signified by 
Chandler (1962: 13), who defined strategy as "the determination of the basic longterm goals and objectives of an enterprise, and the adoption of courses of action and the allocation of resources necessary for carrying out these goals".

Following this understanding of strategy, consistency is a constituent element of strategy. According to Milgrom and Roberts (1992) strategic consistency avoids conflicts between multiple strategic goals or multiple measures to realize a certain strategic advantage, or that "doing more of any activity increases (or at least does not decrease) the marginal profitability of each other activity in the group" (Milgrom and Roberts 1992: 108). Similar, Porter (1996: 71) argued that "consistency ensures that the competitive advantage of activities cumulate and do not erode or cancel themselves out".

Strategic consistency is not consistently defined, a fact that is expressed by the variety of associated concepts (Lamberg et al. 2009). Consistency is a relational concept, as it associates two or more objects with each other. We follow the congruency-consistency systematization of Mintzberg (1979), who distinguishes between conditions and organizational parameters. Congruency means that the conditions and organizational parameters fit, and consistency means that the organizational parameters are compatible. Thus, strategic consistency can be interpreted as the consistency of strategic measures. By applying this understanding of strategic consistency to our research, we define strategic consistency as the coherence of strategic actions within an M\&A series or, more precisely, the coherence of serial acquisitions and their strategic direction.

From a transfer theoretical perspective, positive effects of strategic consistency are expected in two dimensions: First, positive transfer effects are expected when executing transactions of similar kind. For example the experience gained when integrating a target should be especially applicable, when transactions have the same direction. The process of integrating an acquired target and reorganizing the organization makes organizations unstable. The situation is characterized by a high level of uncertainty and imperfect information (Hannan and Freeman 1984). Taking into consideration the above-mentioned functionality of strategic consistency, we propose that strategic consistency can be a means to overcome this unstable situation and successfully manage the integration process.

Second, Milgrom and Roberts (1992) adjudge that strategic consistency provides an opportunity to deal with imperfect information in a rapidly changing environment. The coordination function of strategic consistency and its positive impact on performance is emphasized by several researchers; for example, Rumelt (1980: 360) stated that "[i]nconsistency in strategy is not simply a flaw in logic. A key function of strategy is to provide coherence to organizational action. A clear and explicit concept of strategy can foster a climate of tacit coordination that is more efficient than most administrative mechanisms". In a similar way, research from managerial economics highlights the coordination function of strategic consistency. Shared schemas or cognitive maps add to improved information processing, in turn leading to decreased costs of internal coordination. Strategic consistency, in this sense, leads to a dominant general management logic or mental structuring (Prahalad and Bettis 1986). 
These mental or cognitive patterns are also of high relevance in organizational learning theory. They determine whether and how information is perceived, how managers draw inferences from them and, thereby, store the gained knowledge in routines that can influence their future actions (Cyert and March 1963; Levitt and March 1988). Experiences must be codified before they can become knowledge (Zollo and Singh 2004); they are evaluated and woven into the construction of the organization's reality. Inferences drawn from the experience are stored in corporate documents, standard operating procedures, rules, standards of good professional practice, and shared perceptions of "the way things are done around here" (Levitt and March 1988). Consequentially, organizational memory is retained even when important organizational members leave the organization (Weick and Gilfillan 1971; Levitt and March 1988). Interpretation of experiences-on the individual as well as the organizational level-depends on the cognitive schemes and knowledge structures of both individuals and organizations (Daft and Weick 1984; Walsh 1995). This means that information processing on both the individual and organizational level is influenced by prior experiences. Knowledge structures allocate attention (White and Carlston 1983), enable encoding (Cohen 1981), retrieval from memory (Anderson and Pichert 1978; Cantor and Mischel 1977), and help interpret experiences (Bower et al. 1979) (for details, please see Walsh 1995). Pursuant to organizational learning theory, learning effects are influenced by cognitive patterns, among other things, determining perceptions and conclusions, as well as by the similarity of antecedent situations (Haleblian and Finkelstein 1999).

In line with the theoretical premises outlined above, our basic assumption is that there are positive transfer effects of strategic consistency within acquisition series, resulting in a positive relationship between strategic consistency and performance of serial acquisitions. Particularly, if such positive transfer effects are assumed or can be observed by the capital market, consistency-assumed to be effective-will result in higher abnormal returns due to increased perceived efficiency within the organization.

The direction of acquisitions is a good externally detectable indicator for intraseries strategic consistency in strategic actions. Hence, the prediction is this: the higher the level of concordance in strategic actions - understood in this study as strategic directions of acquisitions within a series - the higher the level of strategic consistency.

Therefore, in line with our aim to analyze the consistency of strategic actions, our first hypothesis is as follows:

Hypothesis 1: there is a positive relationship between strategic consistency-in the form of the level of concordance in strategic directions of acquisitions within a series_-and performance of serial acquisitions.

Further, we extend the concept of similarity in a second dimension, the temporal perspective. As outlined above, the consideration of the chronology is valuable and is expected to shed light on the performance implication of acquisition series. By not taking into consideration the chronological order, we would risk not exploiting the full potential of series analysis.

Therefore, we explicitly consider the chronological order of the executed acquisitions belonging to a series and analyze the strategic direction of these 
acquisitions. Hence, the prediction is this: the lower the frequency of change in strategic actions, the higher the level of strategic consistency. Our second hypothesis is as follows:

Hypothesis 2: there is a positive relationship between strategic consistency-in the form of the frequency of change in strategic directions of acquisitions within a series-and performance of serial acquisitions.

\section{Empirical study}

To explore the hypotheses, our research model contains strategic consistency as an explanatory factor for serial acquisition performance. In order to measure serial acquisition performance as a dependent variable, we use cumulative abnormal return (CAR) and therefore are measuring the collective capital market's expectation regarding the likelihood of success of the announced transaction. Given that acquisition performance is influenced by a set of other factors, we control for contextual and transactional factors as well as for the bidder and the acquisition series process. Hereinafter, we will introduce the sample, the research design and the variables of our empirical study.

\subsection{Sample}

We examined a sample of 1990 serial acquisitions that were part of 379 series, which were announced by 267 listed acquirers from the UK, Germany, and France between January 1st, 1995 and December 31, 2008. Acquirers were listed as of January 1st, 1995, in the FTSE350, HDAX100 or SBF120 indexes or were created through a merger of equals prior to 2008. By choosing this time period, our sample covers several M\&A-cycles. The starting point of 1995 ensures that duties for ad hoc reporting are in place for all three countries. Germany was the last to introduce this duty, on January 1, 1995, due to the implementation of the second capital market support law (Zweites Finanzmarkt-förderungsgesetz) and $\$ 15 \mathrm{WpHG}$ (the Securities Trading Act). To be included in the sample, acquirers must have been clearly identifiable in Worldscope, Datastream, and Thomson Financial SDC and not part of the financial services industry (SIC 6000-6999). Furthermore, accounting data in the fiscal year prior to the announcement date of an acquisition had to be available in Worldscope, and capital market data up to 10 days before as well as 10 days after the announcement date had to be available in Datastream.

In the next step, we created an acquisition sample using the information from the Mergers \& Acquisitions (M\&A) database of Thomson Financial SDC and by adding missing information from mergermarket. In order to be included in the sample, the acquisition must have been reported as completed by a maximum of 1000 days after the announcement date (Moeller et al. 2004). The bidder must have controlled less than 50 percent of the target shares prior to and more than 50 percent after the acquisition (Fuller et al. 2002). For each acquisition, information on either deal value or target sales must have been available one fiscal year prior to the announcement date. The acquisition had to have a relative size of at least one 
percent (Masulis et al. 2007), measured as an index of target sales to bidder sales and/or deal value to bidder market capitalization 20 days before the announcement date of the acquisition. Based on this criteria set, the initial sample consisted of 2,220 acquisitions announced by 329 bidders.

In the second step, we derived the series sample based on the acquisition sample using the following selection criteria: The series must have contained at least two acquisitions in direct succession. The acquisitions had to have been announced within a maximum time interval of 730 days (2 years). The approach follows Hopkins (1987), Gregory (1997) and Ismail (2008) who define similar minimum specifications for the existence of series. In order to avoid a bias resulting from a cutout of the period under consideration out of the whole acquisition series of a company, transactions were included in the sample only if the respective company did not execute any transactions in the two previous years (1993 and 1994). By doing so, we were able to ensure, that the series started within the time window under consideration and not prior to the starting point of our sample. The selection resulted in a final sample of 379 series consisting of 1,990 serial acquisitions by 267 firms.

\subsection{Model design}

Beyond descriptive, univariate analysis, we applied the method of multivariate regression. With respect to the intended explanatory objective-the coherence between strategic consistency and performance of acquisitions-we employed an ordinary least squares (OLS) model.

Within our basis model, we distinguished two analysis levels. On level I, the effect of transaction- and context-related variables was isolated in a separate regression model in advance. This level served to isolate the typical transaction- and context-related influencing factors of transaction performance, already verified in previous research studies on single transactions (Fahlenbrach 2009). Resultant of the level I regression are its residuals. Thus, level I regression can be viewed as a medium for filtering out pure transaction-related factors validated for single transactions.

The level II regression examined the relationship between strategic consistency as an explanatory variable and the residuals of level I: Hence, indirectly, the relationship between consistency-related variables and abnormal returns is examined.

The level I regression features an OLS model based on the following equation:

$$
A_{i}=\alpha+\beta K_{i}+\varepsilon_{i, \mathrm{I}}
$$

for each (serial) acquisition $i$ and the vector of control variables $K$.The OLS model on level II is derived from level I and is based on the following equation:

$$
\varepsilon_{i, I}=\alpha+\gamma E_{i}+\delta K_{i}+\varepsilon_{i, \mathrm{II}}
$$

For each (serial) acquisition $i$, the vector of explanatory variables $E$, and control variables $K$, respectively. 


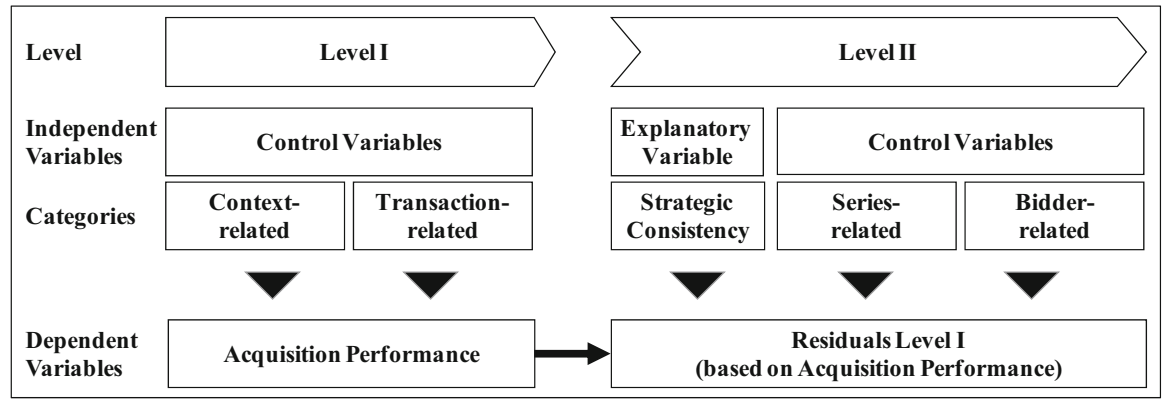

Fig. 1 Model structure and variable categories

Figure 1 visualizes the two-level regression model structure and the respective variable categories employed.

The core of the tiering is the differentiation of series-related and non-seriesrelated variables, hence the point in time of measuring the variables. Distinct transaction-related and non-series-related factors are measured for each transaction. Series-related variables reflecting strategic consistency and several control variables are measured for each serial acquisition, but their characteristics are measured cumulatively, depending on the respective acquisition rank in the series. Bidderrelevant variables are recorded prior to the beginning of a series and not for each acquisition.

The differentiation between levels I and II is pivotal for the setup of the following model, its variables and statistical inference. In conclusion, we would like to highlight three particularities. First, regarding applied independent variables, the analysis is oriented toward the cumulative perception of the capital market. Second, by definition, an acquisition series has to consist of at least two acquisitions; therefore, only acquisitions with series ranks equal to or higher than two are included in the analysis on level II. Third, a regression analysis on level I covers typical transaction-related influencing factors on abnormal returns for all transactions of our sample. Regressions on level II intend to explain the remaining residuals from level I by series-related variables.

\subsection{Dependent variables}

Our focus is to examine the effect of strategic consistency on the expected performance of serial acquisitions. The existing M\&A literature has employed a range of performance measures, mainly in two categories: accounting-based performance measures and stock performance indicators. The main disadvantage of measures based on financial statements is the time of measurement, that is, the time lag between execution and reporting (Chakravarthy 1986). The financial impact of an acquisition is elusive based on annual accounts; the single effects are not assignable. On the contrary, the short-term time window of stock performance indicators offers the advantage of time sensitivity toward the respective event by closely linking the measurement of the effects to the event under investigation and 
excluding the effects of any other subsequent event possibly overlaying the direct effect or preventing exploitation of the acquisition's full potential. Therefore, we use the CAR of a bidding company at the time of the announcement of the acquisition as a dependent variable on level I. Although, using this dependent variable is standard not only in M\&A research (Betton et al. 2009; Boone and Mulherin 2008; Lehn and Zhao 2006; Malmendier and Tate 2008), but also when it comes to analyze learning effects of serial acquirers (e.g., Haleblian and Finkelstein 1999; Hayward 2002), we would like to highlight one important particularity. In the logic of event studies, information transported via the announcement of an acquisition will be directly_positively or negatively_priced in. Therefore, stock performance indicators reflect the collective expectation of the capital market regarding the likelihood of success or performance of the respective announced transaction (Oler et al. 2008) and not the effective performance. Zollo and Meier (2008) view it as a collective bet on the performance of the acquisition. To be precise, in our research setting, this means that we measure perceived transfereffects, namely those that the market assumes will become effective. This aspect reveals an important premise of event studies, namely the rationality and efficiency of capital markets - a premise that is controversially discussed (for details, please refer to Fama (1970); for its validity in the context of M\&A, see Haleblian and Finkelstein (1999), Jensen and Ruback (1983) and Oler et al. (2008)). As the direction of acquisitions is a good externally detectable piece of information available at the time of the announcement of the transaction, we follow the premise of informationally efficient capital markets.We follow Brown and Warner's (1985) standard event study methodology to calculate CARs as follows:

$$
C A R_{i, t}=\sum_{t=1}^{n} A R_{i, t}
$$

for the abnormal return AR of the acquirer $\mathrm{i}$ over $\mathrm{n}$ days $\mathrm{t}$ of the time window.

Following Fuller et al. (2002), we calculate CARs for the five-day period [-2; $+2]$ around the announcement date. Variations for robustness tests include the time windows $[-1,+1]$ and $[-5 ;+5]$ and winsorized abnormal returns. Fuller et al. (2002) reason that, for frequent acquirers, the probability is quite high that previous takeover attempts will be included in the estimation period, thus making beta estimations less meaningful. Therefore, we follow their approach and estimate the abnormal returns using the following modified market model:

$$
A R_{i, t}=R_{i, t}-R_{m, t}
$$

where $r_{i, t}$ is the return for firm i on day $t$ and $R_{m, t}$ is the value-weighted market index return on day $t$. The benchmarks for the calculation of the market returns are the capital-weighted performance indices of the countries under consideration: for Great Britain, the FTSE All Share; for Germany, the CDAX; and for France, the SBF 250. The parameters have been estimated over a [ -10 days; -200 days] interval.

In order to examine acquisition performance on level II, we used residuals of the level I regression. 


\subsection{Measurement of strategic consistency}

The explanatory variable is strategic consistency. In order to measure for strategic consistency, we followed a two-step approach. First, we rated each acquisition regarding its strategic direction, following Haunschild (1994). An acquisition is considered to be horizontal when the target's primary SIC matches the bidder's SIC on a four-digit level. Acquisitions are classified as related if this match occurs on a two-digit level and there is no vertical relationship between bidder and target. An acquisition is considered to be vertical if it is not horizontal and a bidder receives or delivers more than five percent of its consumed or produced goods from or to a target (Fan and Lang 2000; McGuckin et al. 1991). An acquisition is classified as conglomerate if none of the criteria above hold.

In a second step, we used the results of this analysis in order to measure actionrelated strategic consistency. In line with our hypotheses outlined above, strategic consistency is measured as the cumulated rate of concordance of strategic directions (CONCORDANCE), or alternatively, as the cumulated fliprate (FLIPRATE) of strategic directions. We compared each transaction with its predecessor and analyzed whether they are of the same acquisition direction. If yes, they are concordant and no flip occurs. Hence, the CONCORDANCE increases. If the transactions are not of the same acquisition direction, they are not concordant, a flip occurs and the FLIPRATE increases. In order to eliminate the effect of a random pattern of concordance or fliprates in a series, we modified the consistency-related variables by using a randomized component. The actual cumulated concordance or fliprate is calculated against an expected value of the cumulated concordance or fliprate at a specific series rank. The variables are defined as follows:

$$
\begin{gathered}
\operatorname{CONCORDANCE}_{i b}=\left(\frac{a}{c}\right)_{i b}-E\left(\frac{a}{c}\right)_{i r b} \\
\text { FLIPRATE }_{i b}=\left(\frac{h}{j}\right)_{i b}-E\left(\frac{h}{j}\right)_{i r b} .
\end{gathered}
$$

For each focal serial acquisition $i$ by bidder $b$, where $a$ is the number of actual cases of concordance in the series up to the focal acquisition, $c$ is the number of possible cases of concordance up to the focal acquisition at series rank $r, h$ is the actual number of flips, $j$ the possible number of flips, and $\mathrm{E}$ is the expected value.

The calculation of the expected cumulated rate of concordance for each series rank $\mathrm{r}$ is based on a multinomial distribution function. The calculation of the expected cumulated fliprate for each series rank $\mathrm{r}$ is based on a binomial distribution function. For further details please refer to the Appendix A. Further, we used a short-term variable FLIP, measuring a change of strategic directions between a focal serial acquisition and the previous serial acquisition.

\subsection{Additional control variables}

Previous M\&A research indicates that a number of variables, both at the individual and serial level, may influence performance of M\&A series and should therefore be 
controlled for. Coherent with our model design, we distinguished two types of control variables. The first type consists of control variables immediately related to an isolated transaction and are therefore context- or transaction-specific. The second type of control variable has serial character and is therefore related to a series or related to bidders. As a transaction-specific control variable, RELATIVE SIZE between bidder and target (Moeller et al. 2004; Seth 1990) is defined as the index of bidder sales to target sales and deal value to market capitalization as a percentage. Other binary control dummy variables include (1) PUBLIC, for listed target companies (Chang 1998, Officer 2007); (2) CASH, for purchase price payments in cash (Faccio and Masulis 2005; Travlos 1987); (3) HOSTILE, for transactions with a hostile attitude (Franks and Mayer 1996; Loughran and Vijh 1997); (4) TOEHOLD, for previous minority shareholdings (Betton et al. 2009; Franks and Harris 1989); (5) CROSSBORDER, for foreign targets (Goergen and Renneboog 2004; Rossi and Volpin 2004); and (f) CONGLOMERATE, for conglomerate acquisition direction (Healy et al. 1992; Morck et al. 1990). Regarding the latter control variable, CONGLOMERATE, it is important to highlight that this information is used in order to filter out the effect on each single transaction. On level II, however, the classification as conglomerate acquisition-respectively as vertical, horizontal or related-is used in order to derive the explanatory variables. On level I, the information that an acquisition is conglomerate is used directly as a control variable; on level II, this information is only used indirectly as an auxiliary quantity in order to determine the explanatory variables. In line with existing M\&A research, we controlled for external factors influencing abnormal returns and used context-specific dummy variables for year, industry, and country effects (Fowler and Schmidt 1989; Moeller et al. 2004).

Series-related control variables include three variables: (1) VARIATION as percent standard deviation relates to changes in relative acquisition size between bidder and target over the course of a series; (2) TIME can be described as the cumulated average time interval in days between acquisitions in a series (Hayward 2002; Kusewitt and Junior. 1985; Vermeulen and Barkema 2001); and (3) the dummy variable LOSS takes a value of 1 for a focal serial acquisition in case there has been a small loss in CAR in its previous serial acquisition. Small is defined as negative cumulated abnormal returns between 0 and 3 percent (Hayward 2002). Further, we added the variable Acquirer-Target-Similarity (ATS) as a crosscalibration of existing concepts in organizational learning literature. Finkelstein and Haleblian (2002), for example, argue that positive transfer will be more likely the higher the extent to which the industrial environment of the acquirer is similar to that of the target company. Based on Morck et al. (1990) and as Haleblian and Finkelstein (1999), Finkelstein and Haleblian (2002) and Hayward (2002) do, we measure ATS using SIC codes. We adjusted the variable such that it is cumulated up to the focal serial acquisition and weighted with the number of announced acquisitions in the series up to the focal acquisition.

As characteristics of a bidder company are relevant to the performance of acquisitions, we controlled for size effects among bidders, shareholder structure, the existence of future, profitable investment opportunities, available cash, and leverage of the bidder. Therefore, we used the following variables that are pervasive in well- 
reputed M\&A literature: (1) SIZE, defined as the natural log of total bidder assets (Moeller et al. 2004); FREEFLOAT, defined as the percentage of shares not closely held (Dahlquist et al. 2003; Moeller and Schlingemann 2005); TOBINSQ, approximated by the bidder's market-to-book ratio (Bargeron et al. 2008; Moeller et al. 2004); FREECASH, defined as a bidder's free cash flow in percent of total assets (Lehn and Poulsen 1989); and LEVERAGE, defined as a bidder's long-term debt as a percentage of total assets (Faccio et al. 2006; Rhodes-Kropf et al. 2005). Moreover, we reflect the current level of diversification among bidders by using the variable "ENTROPY". This variable is measured based on the definition by Jacquemin and Berry (1979) capturing a related and unrelated part of diversification. In order to eliminate serial effects on bidder characteristics, the time of measurement is prior to the beginning of an acquisition series and not prior to each acquisition. Table 1 provides the sample descriptive statistics and correlations for all variables discussed above.

\section{Results}

Corresponding to our research design, we first present the results of the multivariate analysis on level I dedicated to the transaction and context-related effects before then analyzing the effects of strategic consistency.

\subsection{Multivariate analysis on level I: transaction- and context-related effects}

The purpose of the OLS regression on level I is to isolate transaction- and contextrelated effects. Table 2 shows results from the multivariate regression on level I. Model (I.1) includes key transaction-related control variables, and model (I.2) adds dummy variables on the context-related factors year, industry, and country.

Abnormal returns and the effect of control variables of the level I model confirm the results of existing M\&A research (e.g. Moeller et al. 2004; Fuller et al. 2002; Faccio et al. 2006). With its residuals, model (I.2) serves as a basis for level II regressions, including the analysis on strategic consistency as an explanatory variable.

\subsection{Multivariate analysis on level II: effects of strategic consistency}

The purpose of OLS regression on level II is to explain the remaining residuals from level I by series related variables. In order to analyze the relationship between strategic consistency and abnormal returns, we constructed five models on level II. Table 3 presents our model versions (II.0) through (II.4) based on the residuals of model (I.2) from level I. Model (II.0) is the basis model without any independent variable. Model (II.1) is the standard model of level II analysis, featuring CONCORDANCE as the key explanatory variable. Model (II.2) includes FLIPRATE instead of CONCORDANCE. In model (II.3), we replaced FLIPRATE with FLIP. In a slightly changed model setup (II.4), we include dummy variables for series ranks assigned to a particular focal serial acquisition. 


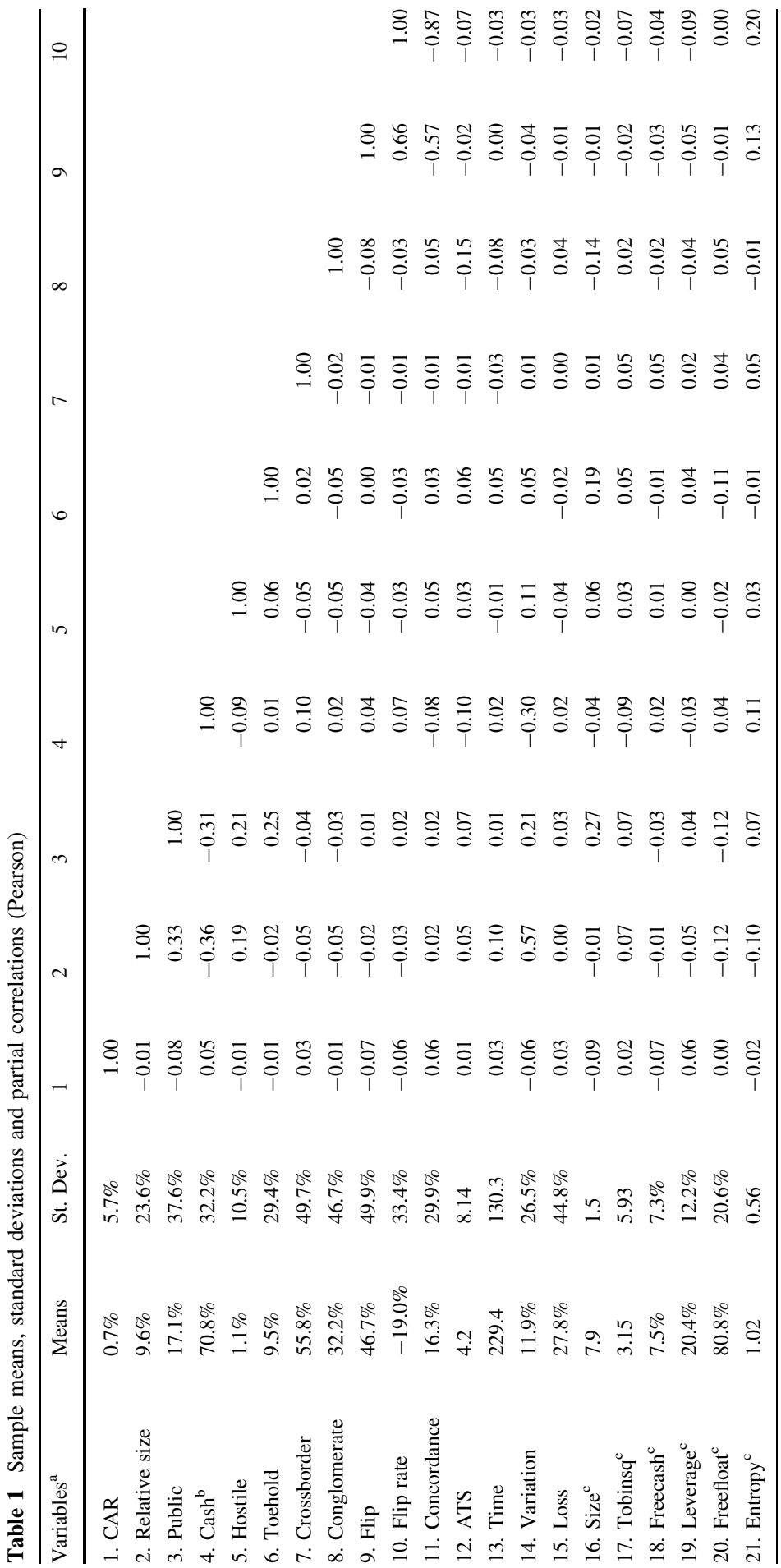




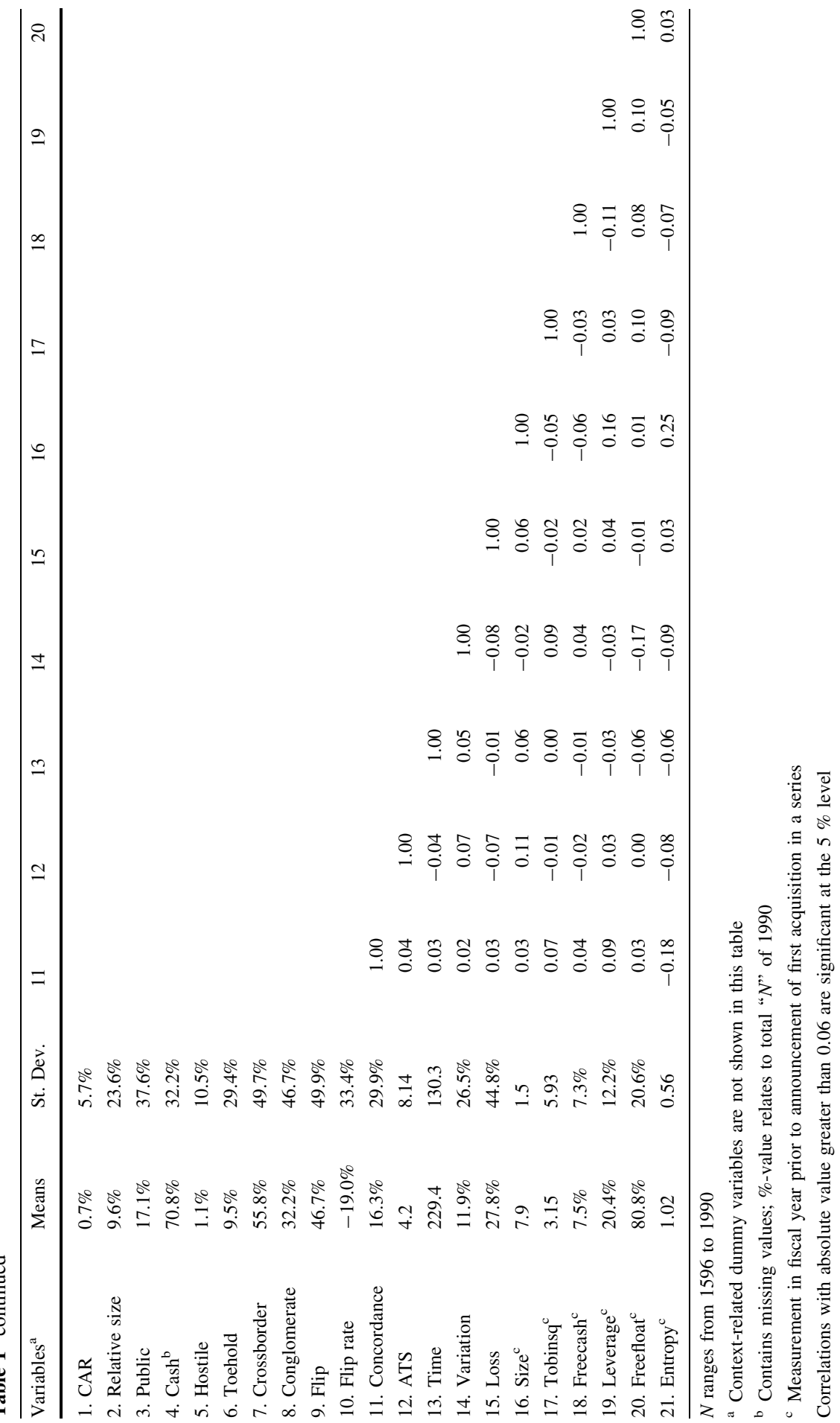


Table 2 Level I-Effect of transaction- and context-related variables

\begin{tabular}{|c|c|c|c|c|}
\hline & \multirow{2}{*}{\multicolumn{2}{|c|}{ Models }} & \multirow{2}{*}{\multicolumn{2}{|c|}{ (I.2) }} \\
\hline & & & & \\
\hline & \multicolumn{2}{|c|}{ Dep.Var. CAR $[-2 ;+2]$} & \multicolumn{2}{|c|}{ Dep.Var. CAR $[-2 ;+2]$} \\
\hline & $\begin{array}{l}\text { Coeff. sign. } \\
\text { level [t stat.] }\end{array}$ & $p$ value & $\begin{array}{l}\text { Coeff. sign. } \\
\text { level [t stat.] }\end{array}$ & $p$ value \\
\hline Relative size & $0.019 * *[2.12]$ & 0.034 & $0.019 * *[2.07]$ & 0.039 \\
\hline Public & $-0.010 * *[-2.41]$ & 0.016 & $\begin{array}{r}-0.010 * * \\
{[-2.42]}\end{array}$ & 0.016 \\
\hline Cash & $0.011 *[1.85]$ & 0.065 & $0.014 * *[2.36]$ & 0.018 \\
\hline Hostile & $-0.004[-0.33]$ & 0.742 & $-0.003[-0.21]$ & 0.834 \\
\hline Toehold & $0.005[0.98]$ & 0.326 & $0.006[1.13]$ & 0.261 \\
\hline Crossborder & $0.003[1.07]$ & 0.284 & $0.002[0.56]$ & 0.575 \\
\hline Conglomerate & $-0.001[-0.39]$ & 0.697 & $-0.004[-1.11]$ & 0.267 \\
\hline Constant & $-0.004[-0.66]$ & 0.507 & $0.036[0.93]$ & 0.350 \\
\hline $\begin{array}{l}\text { Context-related dummy variables (year, } \\
\text { industry, country) }\end{array}$ & No & & Yes & \\
\hline Regression model & OLS & & OLS & \\
\hline Heteroscedasticity (Breusch/Pagan) & Yes*** & 0.000 & Yes*** & 0.000 \\
\hline Autocorrelation (Wooldridge) & No & 0.705 & No & 0.705 \\
\hline Observations & 1769 & & 1769 & \\
\hline$R^{2}$ & 0.012 & & 0.046 & \\
\hline Adj. $R^{2}$ & 0.008 & & 0.09 & \\
\hline$F$ statistic & 2.30 & & 1.633 & \\
\hline
\end{tabular}

$p$ value: $* * *<0.01 ; * *<0.05 ; *<0.1$

We used White clustered standard errors to mitigate the effect of heteroscedasticity

Overall, we find evidence for a positive impact of strategic consistency in acquisition series on acquisition performance. We measured strategic consistency in a variety of ways; all of them confirm our hypothesis of a positive relationship between strategic consistency and the performance of serial acquisitions.

CONCORDANCE, as an operationalization of strategic consistency in an acquisition series, shows a significantly positive coefficient in model (II.1), supporting hypothesis 1 and indicating a positive relationship between strategic consistency in terms of strategic directions of acquisitions within a series and level I residuals, reflecting acquisition performance after controlling for transaction-related factors. The variable FLIPRATE has an almost inverted behavior compared to CONCORDANCE, showing a significant negative relationship with acquisition performance [see model (II.2)], supporting hypothesis 2 . With respect to the variable FLIP, as illustrated in model (II.3), a strongly significant negative coefficient can be observed. Both variables FLIP and FLIPRATE reflect the frequency of change in strategic actions; the higher the frequency of change, the lower the level of strategic consistency. 


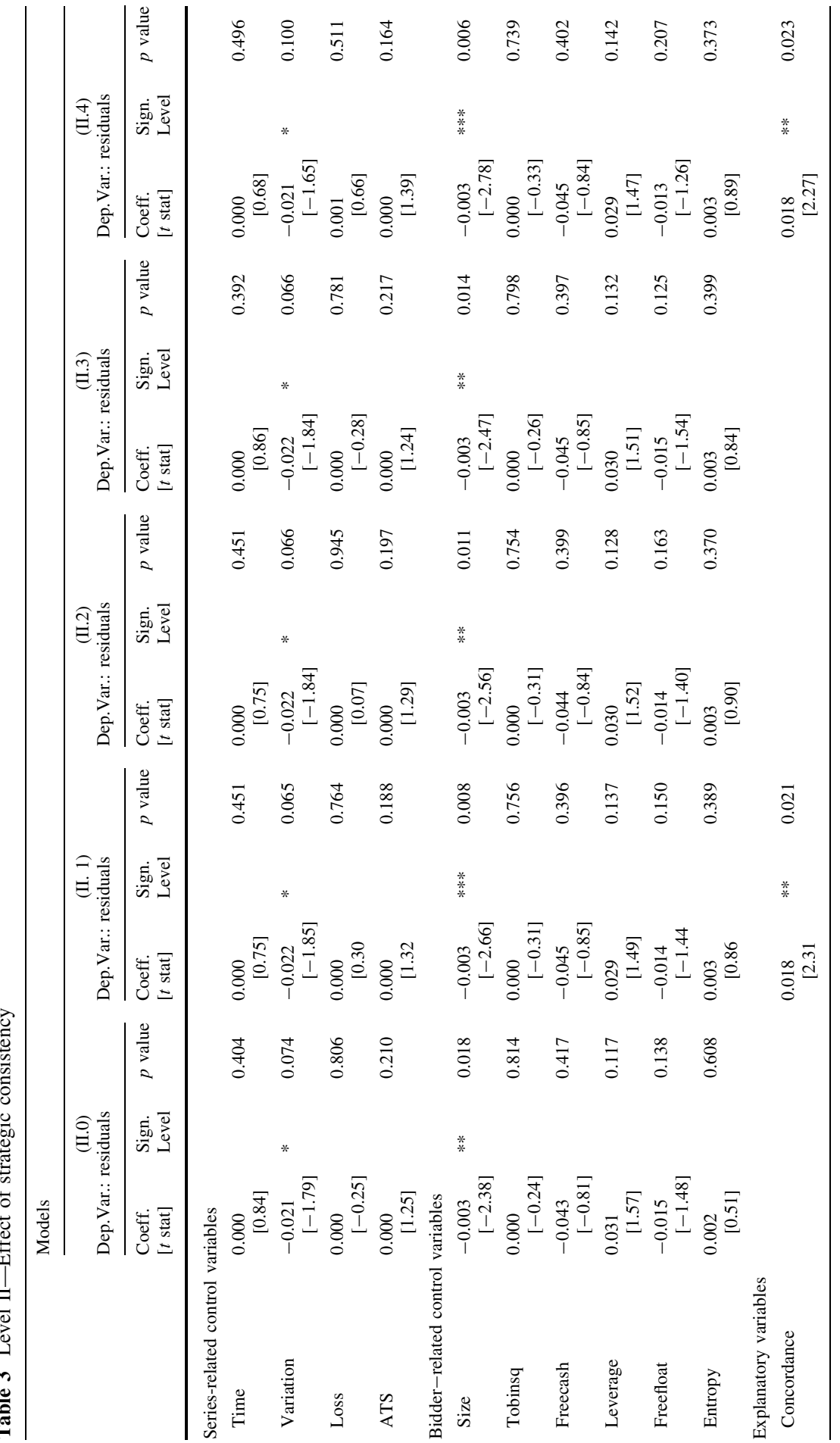




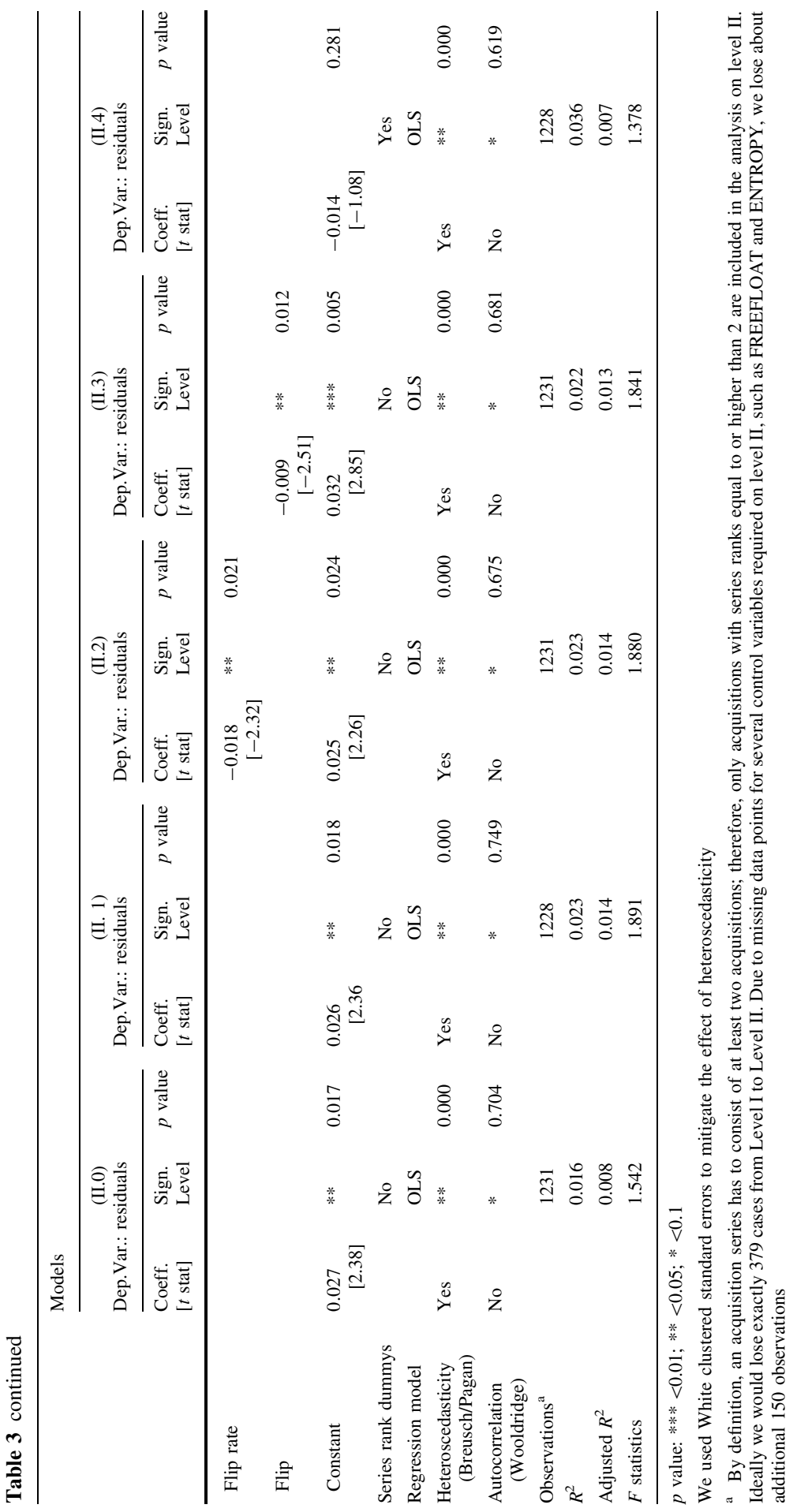


As can be seen in model (II.4), in which we introduced dummy variables for series ranks, no major changes can be observed with regard to the explanatory variable CONCORDANCE. However, the goodness of fit and overall significance of the regression is slightly reduced. Thus, rank effects do not explain a significant share of total variance in the multivariate model setup.

\subsection{Robustness checks and general validity of linear regression model}

In order to overcome general constraints of the quality of linear regression models, we conducted tests for heteroscedasticity, serial correlation, multi-collinearity, endogeneity and normal distribution. We used the Breusch-Pagan test to test for heteroscedasticity. The null hypothesis of homoscedasticity is rejected for all OLS regression setups in this paper. However, we corrected for this issue by applying heteroscedasticity-consistent standard errors and covariance based on White (1980) directly in the regression. Serial correlation was tested using the Wooldridge test. Results of both tests, the Woldridge and the Breusch-Pagan, are reported in Tables 2 and 3. With respect to multicollinearity, we report the maximum variance inflation factors (VIFs) for each variable in Table 4. According to Craney and Surles (2002), values for VIFs equal to or below 5 indicate that the problem of multicollinearity can be rejected. Endogeneity in respect to the explanatory variable may not be expected, as it might not be argued conclusively why abnormal returns should influence the strategic consistency of a series. Omitted variables can never be ruled out. However, our models contain a large variety of all canonic variables of the M\&A literature. By approximation, we analyzed the fundamental assumption of no covariance between independent variables and error terms with an analysis of covariance (Pearson). For none of the control and independent variables, the null hypothesis of absence of covariance with the error terms can by rejected with sufficient enough significance level (see Appendix 2). Normal distribution was tested using a graphical analysis of the residues of Level I and Level II (see Appendix 3), revealing a normally distributed behavior of both groups of residues. To conclude, the problems of linear regression models can be rejected.

The quality and robustness of our conclusions was validated by running regressions with modified specifications in three different ways. First, we removed the control variable ATS from the model, as it was used as a cross-calibration of existing concepts in organizational learning literature. Second, we rerun all the regressions based on a different definition criteria for acquisitions belonging to a series. The acquisitions did not have to be announced within a maximum time interval of two years, but within a maximum time interval of (a) three, (b) four and (c) five years. Further, we treated each acquirer as one series. These new series definitions were used to rerun regressions on the original sample, as well as on an adapted sample. In the later case the starting point of each series was identified by taking into consideration a timeout of three, four and five years respectively before the first acquisition of a series. Third, we modified our dependent variable on level I: the CARs were calculated on the alternative time windows $[-1,+1]$ and $[-5 ;+5]$. Further we made results robust against outliers by winsorizing the CARs (all three time windows) by a maximal deviation of three times standard deviation from mean. All modifications resulted in qualitatively the same results. Results for all robustness tests are available upon request. 
Table 4 Variance inflation factors (VIFs)

\begin{tabular}{|c|c|c|c|c|c|c|}
\hline \multirow[t]{2}{*}{ Level I } & & & \multicolumn{4}{|c|}{ Models } \\
\hline & & & \multicolumn{3}{|l|}{ I. 1} & \multirow{2}{*}{$\frac{\mathrm{I} .2}{\mathrm{VIF}}$} \\
\hline Variable & & & \multicolumn{3}{|l|}{ VIF } & \\
\hline Public & & & \multicolumn{3}{|c|}{1.23} & 1.33 \\
\hline Cash & & & \multicolumn{3}{|l|}{1.18} & 1.25 \\
\hline Relative size & & & \multicolumn{3}{|l|}{1.17} & 1.21 \\
\hline Hostile & & & \multicolumn{3}{|l|}{1.06} & 1.10 \\
\hline Toehold & & & \multicolumn{3}{|l|}{1.06} & 1.12 \\
\hline Crossborder & & & \multicolumn{3}{|l|}{1.01} & 1.12 \\
\hline Conglomerate & & & \multicolumn{3}{|l|}{1.01} & 1.12 \\
\hline Max. VIF & & & \multicolumn{3}{|l|}{1.23} & 1.33 \\
\hline \multirow[t]{2}{*}{ Level II } & \multicolumn{6}{|c|}{ Models } \\
\hline & II.0 & II.1 & & II. 2 & II. 3 & II.4 \\
\hline Variable & VIF & VIF & & VIF & VIF & VIF \\
\hline \multicolumn{7}{|c|}{ Series-related control variables } \\
\hline Time & 1.05 & 1.05 & & 1.05 & 1.05 & 1.07 \\
\hline Variation & 1.06 & 1.06 & & 1.06 & 1.06 & 1.11 \\
\hline Loss & 1.13 & 1.14 & & 1.14 & 1.13 & 2.53 \\
\hline ATS & 1.04 & 1.04 & & 1.04 & 1.04 & 1.09 \\
\hline \multicolumn{7}{|c|}{ Bidder-related control variables } \\
\hline Size & 1.14 & 1.14 & & 1.14 & 1.14 & 1.19 \\
\hline Tobinsq & 1.04 & 1.04 & & 1.04 & 1.04 & 1.04 \\
\hline Freecash & 1.05 & 1.05 & & 1.05 & 1.05 & 1.06 \\
\hline Leverage & 1.09 & 1.09 & & 1.09 & 1.09 & 1.10 \\
\hline Freefloat & 1.07 & 1.07 & & 1.07 & 1.07 & 1.12 \\
\hline Entropy & 1.17 & 1.19 & & 1.19 & 1.19 & 1.20 \\
\hline \multicolumn{7}{|c|}{ Explanatory variables } \\
\hline Concordance & & 1.04 & & & & 1.11 \\
\hline Fliprate & & & & 1.05 & & \\
\hline Flip & & & & & 1.02 & \\
\hline Max. VIF & 1.17 & 1.19 & & 1.19 & 1.19 & 2.53 \\
\hline
\end{tabular}

\section{Discussion and conclusion}

\subsection{Implications and contribution}

The aim of this study was to shed additional light on our understanding of the relationship between acquisition experience and acquisition performance. By applying transfer theory, we analyzed whether strategic consistency—signifying the 
similarity of strategic direction of acquisitions - has positive performance effects on serial acquisitions. Based on a sample of 379 series consisting of 1990 serial acquisitions, we have found evidence for a significantly positive relationship between strategic consistency and acquisition performance in terms of CAR. The relationship holds true for the rate of concordance of strategic directions in a series and-inversely negative-for the rate of changes of directions.

From a conceptual point of view, we believe the study makes an important contribution in three dimensions. First, our study contributes to the organizational learning literature to the effect that we combine two different research streams that have evolved over time separately: research on negative experience transfer and research on deliberate learning mechanisms (see Barkema and Schijven 2008b for an overview). By analyzing the transfer effects of strategic consistency and, therefore, shifting the perspective from the similarity of targets to the kind of transaction, we were able to shed additional light on the kind of experience that is helpful for organizational learning mechanisms in strategic management settings. Acquisitions offer the possibility to analyze the transfer effects of strategic consistency, as they are discrete and observable strategic management decisions (see also Haleblian and Finkelstein 1999 as well as Finkelstein and Haleblian 2002). In a similar way, the analysis of the role strategic consistency is playing in organizational learning offers us a deeper insight into how acquirers develop and adapt competencies to execute individual acquisitions as well as to manage acquisition series (see Laamanen and Keil 2008 for a differentiation of different layers of acquisition capability development). Strategic consistency provides managers with the ability to draw inferences from prior acquisitions and transfer the gained knowledge, developed processes and routines to the focal acquisition where applicable. Further, strategic consistency provides managers with direction within the strategic decision-making process, thus helping to manage the overall acquisition program.

Second, the results empirically support the theoretical approach of several theoretical research studies analyzing strategic consistency. The study provides an expansion of empirical research on strategic consistency by analyzing externally and clearly detectable strategic management decisions based on a large-scale sample. One reason for the quantitative under-representation of research studies analyzing strategic consistency of strategic management decisions might be that they are externally hard to comprehend and, therefore, hard to measure. Here, again, analyzing M\&A series provides the possibility to overcome this limitation. In our study, we analyze the consistency of empirically identifiable decisions with historical decisions of similar type and challenge their performance relevance.

Third, our study provides two managerial implications. On the one hand, we hope our study will contribute to the improvement in discrimination and generalization by management. By taking into consideration the aspect of strategic consistency, managers will be provided with a different cognitive mindset and different discrimination criteria for their decisions as to whether to draw upon previous gained acquisition experience. Our results suggest that drawing inferences from experience based on strategic consistency will lead to a more appropriate integration of the acquired target, to a higher exhausting of synergy effects and, lastly, higher 
performance or a lower rate of unsuccessful acquisitions. On the other hand, the study emphasizes the perception of strategic consistency of external market participants when evaluating the advantageousness of transactions. They do look for externally observable signals of strategic consistency, such as concordance and a low fliprate. Therefore, they evaluate the consistency of each single transaction with the overall corporate strategy as well as with other previously executed acquisitions. Coherent and consistent strategic moves are far easier to accept than inconsistent decisions. Or, as expressed by Lamberg et al. (2009: 50), "inconsistent actions may decrease the firm's legitimacy among important stakeholders" and lead to undesired actions by them (Pfeffer and Salancik 1978; Meyer and Rowan 1977). Managers should take this into consideration when communicating the strategic goal of the envisaged transaction.

To summarize, our study complies with recent calls to further strengthen the research stream on acquisition programs and, in doing so, adds to the organizational learning literature in strategic management settings.

\subsection{Limitations and outlook}

The limitations of this study offer opportunities for improvement. They can be subdivided into two dimensions: methods and interpretations.

First, the methodology used to measure strategic directions based on SIC is subject to controversial discussions (Davis and Duhaime 1992; Hoskisson et al. 1993; Robins and Wiersema 2003). This paper adds a resource-based dimension by determining vertical relationships between bidder and target using a method proposed by Fan and Lang (2000) based on flows of goods and production. For the sake of simplicity, we have not differentiated between forward and backward vertical integration or pure and mixed vertical relationships (Fan and Goyal 2006). The proposed procedure of determining strategic directions is a simplification; however, it appears relatively sophisticated compared to current literature, in which vertical relationships are mostly not taken into account.

Second, with regard to the interpretation of results, the aspect of generalization needs attention. The sample selected from British, German, and French mid-cap to large-cap firms covers around 60 percent of market capitalization in the European Dow Jones 600 index. However, there is still 40 percent uncovered, which urges caution when it comes to generalizing the results for Europe as a whole. Moreover, it is noteworthy that the sample contains firms across all industries, except financial services. Results need to be carefully assessed, since differences exist between industries, especially relating to the measured degree of matches of SIC (Bettis and Hall 1982).

Even with these limitations, however, we believe the study makes an important contribution to the emerging stream of research on serial acquisitions, research on transfer effects and organizational learning in strategic settings, as well as to empirical research on strategic consistency. Our focus was to analyze whether strategic consistency has an effect on the expected performance of serial acquisitions. To further seize the coupling of the pattern and learning streams of research of acquisition series, succeeding studies could start from here and analyze 
differences in patterns of acquisition direction and search for optimal patterns. Further studies of strategic consistency in acquisition programs may include divestment decisions, as they are generally an integral part of restructuring programs. We look forward to studies that extend the strategic consistency concept toward a congruency-related approach, also incorporating the fit of serial acquisitions to external contingencies and competitive changes (Lamberg et al. 2009). Methodically, the innovative approach of cumulative capital market perception offers room for further development and application beyond the context of acquisition series.

Open Access This article is distributed under the terms of the Creative Commons Attribution 4.0 International License (http://creativecommons.org/licenses/by/4.0/), which permits unrestricted use, distribution, and reproduction in any medium, provided you give appropriate credit to the original author(s) and the source, provide a link to the Creative Commons license, and indicate if changes were made.

\section{Appendix A Calculation of the expected cumulated rate of concordance and fliprate}

The calculation of the expected cumulated rate of concordance for each series rank $r$ is based on a multinomial distribution function:

$$
f\left(X_{r}=k_{1}, k_{2}, \ldots, k_{\mathrm{s}} ; n, p_{1}, p_{2}, \ldots, p_{\mathrm{s}}\right)=\frac{n !}{k_{1} ! \cdot k_{2} ! \cdot \ldots \cdot k_{\mathrm{s}} !} \cdot p_{1}^{k_{1}} p_{2}^{k_{2}} \cdot \ldots \cdot p_{\mathrm{s}}^{k_{\mathrm{s}}}
$$

This function expresses the probability for a certain manifestation of the random variable $X$. This random variable is characterized as tuple of manifestations of the event classes $k$ at a series rank $r$ at $n$ present acquisitions. $k$ includes the four different acquisition directions. They have the same probability of occurrence $p$. For each tuple, the most occurring event class $k$ at $n$ present acquisitions the cumulated concordance is calculated. In order to derive the expected value $E$, all occurring manifestations of concordance are multiplied by the above-calculated probability $X$.

The calculation of the expected cumulated fliprate for each series rank $\mathrm{r}$ is based on a binomial distribution function, as only two events (change of direction: yes or no) are of relevance:

$$
f\left(X_{r}=k ; n\right)=\left(\begin{array}{l}
n \\
k
\end{array}\right) p^{k} q^{n-k}
$$

for the random variable $X$ at series rank $r$; event class $k$ and number of acquisitions $n$.

See Appendix Table 5

See Appendix Fig. 2 
Table 5 Test assumptions linear regression - Endogenity

\begin{tabular}{|c|c|c|c|c|}
\hline & \multicolumn{2}{|c|}{ Error Term* Level I } & \multicolumn{2}{|c|}{ Error Term* Level II } \\
\hline & Covariance & $p$ value & Covariance & $p$ value \\
\hline \multicolumn{5}{|c|}{ Independent variables Level I } \\
\hline Relative size & 0.000 & 1.000 & & \\
\hline Public & 0.000 & 1.000 & & \\
\hline Toehold & 0.000 & 1.000 & & \\
\hline Cash & 0.000 & 1.000 & & \\
\hline Hostile & 0.000 & 1.000 & & \\
\hline Crossboarder & 0.000 & 1.000 & & \\
\hline Conglomerate & 0.000 & 1.000 & & \\
\hline Country dummy & 0.000 & 1.000 & & \\
\hline Industry dummy & 0.000 & 1.000 & & \\
\hline Year dummy & 0.000 & $>0.800$ & & \\
\hline \multicolumn{5}{|c|}{ Independent variables Level II } \\
\hline Entropy & & & 0.000 & 1.000 \\
\hline Concordance & & & 0.000 & 1.000 \\
\hline ATS & & & 0.000 & 1.000 \\
\hline Time & & & 0.000 & 1.000 \\
\hline Variation & & & 0.000 & 1.000 \\
\hline Loss & & & 0.000 & 1.000 \\
\hline Size & & & 0.000 & 1.000 \\
\hline Freecash & & & 0.000 & 1.000 \\
\hline Tobinsq & & & 0.000 & 1.000 \\
\hline Leverage & & & 0.000 & 1.000 \\
\hline Free float & & & 0.000 & 1.000 \\
\hline
\end{tabular}

* Error term corresponds to the residuals of their respective regression
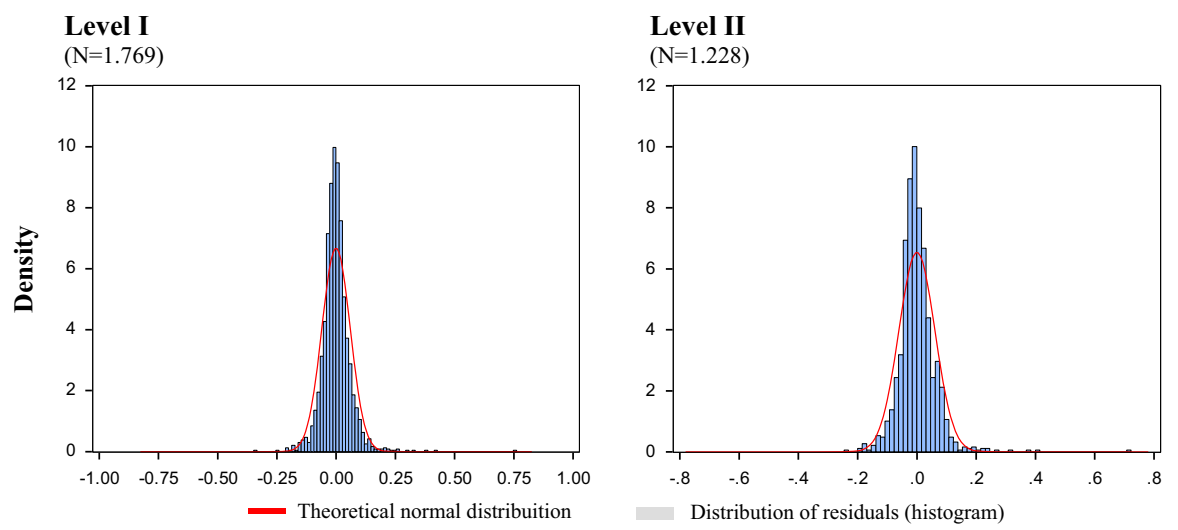

Fig. 2 Normally distributed residuals 


\section{References}

Anderson, Richard C., and James W. Pichert. 1978. Recall of previously unrecallable information following a shift in. perspective. Journal of Verbal Learning and Verbal Behavior 17: 1-12.

Bargeron, Leonce L., Frederik P. Schlingemann, René M. Stulz, and Chad J. Zutter. 2008. Why do private acquirers pay so little compared to public acquirers? Journal of Financial Economics 89(3): 375-390.

Barkema, Harry G., John H.J. Bell, and Johannes M. Pennings. 1996. Foreign entry, cultural barriers, and learning. Stra-tegic Management Journal 17(2): 151-166.

Barkema, Harry G., and Mario Schijven. 2008a. Toward unlocking the full potential of acquisitions: the role of organizational restructuring. Academy of Management Journal 51(4): 696-722.

Barkema, Harry G., and Mario Schijven. 2008b. How do firms learn to make acquisitions? A review of past research and an agenda for the future. Journal of Management 34(3): 594-634.

Bettis, Richard A., and William K. Hall. 1982. Diversification strategy, accounting determined risk, and accounting determined return. Academy of Management Journal 25(2): 254-264.

Betton, Sandra, B. Espen Eckbo, and Karin S. Thorburn. 2009. Merger negotiations and the toehold puzzle. Journal of Financial Economics 91(2): 158-178.

Boone, Audra L., and Harold J. Mulherin. 2008. Do auctions induce a winner's curse? New evidence from the corporate takeover market. Journal of Financial Economics 89(1): 1-19.

Bower, Gordon H., John B. Black, and Terrence J. Turner. 1979. Scripts in memory for text. Cognitive Psychology 11: 177-220.

Brown, Stephen J., and Jerold B. Warner. 1985. Using daily stock returns: the case of events studies. Journal of Financial Economics 14: 3-31.

Campa, José Manuel, and Simi Kedia. 2002. Explaining the diversification discount. The Journal of Finance 57(4): 1731-1762.

Cantor, Nancy, and Walter Mischel. 1977. Traits as prototypes: effects of recognition memory. Journal of Personality and Social Psychology 35: 38-48.

Chakravarthy, Balaji. 1986. Measuring strategic performance. Strategic Management Journal 7(5): 437-458.

Chandler, Alfred. 1962. Strategy and structure-chapters in the history of the American industrial enterprise. Cambridge, MA: The MIT Press.

Chang, Saeyoung. 1998. Takeovers of privately held targets, methods of payment, and bidder returns. The Journal of Finance 53(2): 773-784.

Cohen, C.E. 1981. Person categories and social perception: testing some boundaries of the processing effects of prior knowledge. Journal of Personality and Social Psychology 40: 441-452.

Cording, Margaret, Petra Christmann, and David R. King. 2008. Reducing causal ambiguity in acquisition integration: intermediate goals as mediators of integration decisions and acquisition performance. Academy of Management Journal 51(4): 744-767.

Craney, Trevor A., and James G. Surles. 2002. Model-dependent variance inflation factor cutoff values. Quality Engineering 14(3): 391-403.

Cyert, Richard M., and James G. March. 1963. A behavioral theory of the firm. Englewood Cliffs: Prentice-Hall.

Dahlquist, Magnus, Lee Pinkowitz, René M. Stulz, and Rohan Williamson. 2003. Corporate governance and the home bias. Journal of Financial and Quantitative Analysis 38(1): 87-110.

Daft, R.L., and K.E. Weick. 1984. Toward a model of organization as interpretation systems. Academy Management Review 9: 284-295.

Davis, Rachel, and Irene M. Duhaime. 1992. Diversification, vertical integration, and industry analysis: New perspectives and measurement. Strategic Management Journal 13(7): 511-524.

Ellis, Kimberly M., Taco H. Reus, and Bruce T. Lamont. 2009. The effects of procedural and informational justice in the integration of related acquisitions. Strategic Management Journal 30(2): $137-161$.

Ellis, Kimberly M., Taco H. Reus, Bruce T. Lamont, and Annette L. Ranft. 2011. Transfer effects in large acquisitions: how size-specific experience matters. Academy of Management Journal 54(6): 1261-1276.

Faccio, Mara, and Ronald W. Masulis. 2005. The choice of payment method in European mergers and acquisitions. The Journal of Finance 60(3): 1345-1388. 
Faccio, Mara, John J. McConnell, and David Stolin. 2006. Returns to acquirers of listed and unlisted targets. Journal of Financial and Quantitative Analysis 41(1): 197-220.

Fahlenbrach, Rüdiger. 2009. Shareholder rights, boards, and CEO compensation. Review of Finance 13(1): 81-113.

Fama, Eugene. 1970. Efficient capital markets: a review of theory and empirical work. The Journal of Finance 2: 383-417.

Fan, Joseph P.H., and Harry H.P. Lang. 2000. The measurement of relatedness: An application to corporate diversification. The Journal of Business 73(4): 629-660.

Fan, Joseph P.H., and Vidhan K. Goyal. 2006. On the patterns and wealth effects of vertical mergers. The Journal of Business 79(2): 877-902.

Finkelstein, Sydney, and Jerayr Haleblian. 2002. Understanding acquisition performance: the role of transfer effects. Organization Science 13(1): 36-47.

Fowler, Karen L., and Dennis R. Schmidt. 1989. Determinants of tender offer post-acquisition financial performance. Strategic Management Journal 10(4): 339-350.

Franks, Julian R., and Robert S. Harris. 1989. Shareholder wealth effects of corporate takeovers: The U.K. experience 1955-1985. Journal of Financial Economics 23(2): 225-249.

Franks, Julian, and Collin Mayer. 1996. Hostile takeovers and the correction of managerial failure. Journal of Financial Economics 40(1): 163-181.

Fuller, Kathleen, Jeffry Netter, and Mike Stegemoller. 2002. What do returns to acquiring firms tell us? Evidence from firms that make many acquisitions. The Journal of Finance 57(4): 1763-1793.

Goergen, Marc, and Luc Renneboog. 2004. Shareholder wealth effects of European domestic and crossborder takeover bids. European Financial Management 10(1): 9-45.

Gregory, Alan. 1997. An examination of the long run performance of UK acquiring firms. Journal of Business Finance \& Accounting 24(7\&8): 971-1002.

Haleblian, Jerayr, and Sydney Finkelstein. 1999. The influence of organizational acquisition experience on acquisition performance: a behavioral learning perspective. Administrative Science Quarterly 44(1): 29-56.

Haleblian, Jerayr, Cynthia E. Devers, Gerry McNamara, Mason A. Carpenter, and Robert B. Davison. 2009. Taking stock of what we know about mergers and acquisitions: a review and research agenda. Journal of Management 35(3): 469-502.

Hannan, Michael T., and John Freeman. 1984. Structural inertia and organizational change. American Sociological Re-view 49(2): 149-164.

Haunschild, Pamela. 1994. How much is that company worth? Interorganizational relationships, uncertainty, and acquisition premiums. Administrative Science Quarterly 39(3): 391-411.

Hayward, Mathew. 2002. When do firms learn from their acquisition experience? Evidence from 1990-1995. Strategic Management Journal 23(1): 21-39.

Healy, Paul M., Krishna G. Palepu, and Richard S. Ruback. 1992. Does corporate performance improve after mergers. Journal of Financial Economics 31(2): 135-175.

Hearst, Eliot, and Minnie B. Koresko. 1968. Stimulus generalization and amount of prior training on variable-interval reinforcement. Journal of Comparative and Physiological Psychology 66(1): 133-138.

Hopkins, Donald. 1987. Long-term acquisition strategies in the U.S. economy. Journal of Management 13(3): 557-572.

Hoskisson, Robert E., Michael A. Hitt, Richard A. Johnson, and Douglas D. Moesel. 1993. Construct validity of an objective (entropy) categorical measure of diversification strategy. Strategic Management Journal 14(3): 215-235.

Hutzschenreuter, Thomas, Ingo Kleindienst, and Michael Schmitt. 2012. Path-related empirical research on M\&A-outcome: review and research agenda. Review of Managerial Science 6(4): 375-405.

Hutzschenreuter, Thomas, Ingo Kleindienst, and Michael Schmitt. 2014. How mindfulness and acquisition experience affect acquisition performance. Management Decision 52(6): 1116-1147.

Ismail, Ahmad. 2008. Which Acquirers Gain more, Single or Multiple? Recent Evidence from the USA Market. Global Finance Journal 19: 72-84.

Jacquemin, Alexis P., and Charles H. Berry. 1979. Entropy Measure of Diversification and Corporate Growth. The Journal of Industrial Economics 27: 359-369.

Jensen, Michael C., and Richard S. Ruback. 1983. The market for corporate control: the scientific evidence. Journal of Financial Economics 11: 5-50.

Klarner, Patricia, and Sebastian Raisch. 2013. Move to the beat-rhythms of change and firm performance. Academy of Management Journal 56(1): 160-184. 
Kusewitt, John B. Junior. 1985. An exploratory study of strategic acquisition factors relating to performance. Strategic Management Journal 6(2): 151-169.

Laamanen, Tomi, and Thomas Keil. 2008. Performance of serial acquirers: toward an acquisition program perspective. Strategic Management Journal 29(6): 663-672.

Lamberg, Juhu Antiti, Henrikki Tikkanen, Tomi Nokelainen, and Henri Suur-Inkeroinen. 2009. Competitive dynamics, strategic consistency, and organizational survival. Strategic Management Journal 30(1): 45-60.

Lehn, Kenneth, and Annette Poulsen. 1989. Free cash flow and stockholder gains in going private transactions. The Journal of Finance 44(3): 771-787.

Lehn, Kenneth M., and Mengxin Zhao. 2006. CEO turnover after acquisitions: are bad bidders fired? The Journal of Finance 61(4): 1759-1811.

Levitt, Barbara, and James G. March. 1988. Organizational learning. Annual Review of Sociology 14: 319-340.

Loughran, Tim, and Anand M. Vijh. 1997. Do long-term shareholders benefit from corporate acquisitions? The Journal of Finance 52(5): 1765-1790.

Malmendier, Ulrike, and Geoffrey Tate. 2008. Who makes acquisitions? CEO overconfidence and the market's reaction. Journal of Financial Economics 89(1): 20-43.

Masulis, Ronald W., Cong Wang, and Fei Xie. 2007. Corporate governance and acquirer returns. The Journal of Finance 62(4): 1851-1889.

McGuckin, Robert H., Sang V. Nguyen, and Stephan H. Andrews. 1991. The relationships among acquiring and acquired firms' product lines. Journal of Law and Economics 34(2): 477-502.

Meschi, Pierre-Xavier, and Emmanuel Métais. 2013. Do firms forget about their past acquisitions? Evidence from French acquisitions in the United States (1988-2006). Journal of Management 39(2): 469-495.

Meyer, John W., and Brian Rowan. 1977. Institutionalized organizations: formal structure as myth and ceremony. American Journal of Sociology 83(2): 340-363.

Miles, Raymond E., and Charles C. Snow. 1978. Organizational strategy, structure, and process. New York: McGraw-Hill.

Milgrom, Paul, and John Roberts. 1990. The economics of modern manufacturing: technology, strategy, and organization. The American Economic Review 80(3): 511-528.

Milgrom, Paul, and John Roberts. 1992. Economics, organization and management. Englewood Cliffs, NJ: Prentice- Hall.

Mintzberg, Henry. 1978. Patterns in strategy formation. Management Science 24(9): 934-948.

Mintzberg, Henry. 1979. The structuring of organizations: a synthesis of the research. Englewood Cliffs: Prentice-Hall.

Moeller, Sara B., Frederik P. Schlingemann, and René M. Stulz. 2004. Firm size and the gains from acquisitions. Journal of Financial Economics 73(2): 201-228.

Moeller, Sara B., and Frederik P. Schlingemann. 2005. Global diversification and bidder gains: a comparison between cross-border and domestic acquisitions. Journal of Banking \& Finance 29(3): 533-564.

Morck, Randall, Andrei Shleifer, and Robert W. Vishny. 1990. Do managerial objectives drive bad acquisitions? The Journal of Finance 45(1): 31-48.

Nadolska, Anna, and Harry G. Barkema. 2007. Learning to internationalise: the pace and success of foreign acquisitions. Journal of International Business Studies 38(7): 1170-1186.

Novick, Laura. 1988. Analogical transfer, problem similarity, and expertise. Journal of Experimental Psychology: Learning, Memory and Cognition 14(3): 510-520.

Officer, Micah. 2007. The price of corporate liquidity: acquisition discounts for unlisted targets. Journal of Financial Economics 83(3): 571-598.

Oler, Derek K., Jeffrey S. Harrison, and Matthew R. Allen. 2008. The danger of misinterpreting shortwindow event study findings in strategic management research: An empirical illustration using horizontal acquisitions. Strategic Organization 6(2): 151-184.

Pfeffer, Jeffrey, and Gerald R. Salancik. 1978. The external control of organizations: a resource dependence perspective. New York: Harper \& Row.

Piaskowska, Dorota, Anna Nadolska, and Harry G. Barkema. 2014. Complexity, heterogeneity, and transfer effects of joint venture experience on performance. Academy of Management Proceedings 14(1): 14358.

Porter, Michael. 1980. Competitive strategy: techniques for analyzing industries and competitors. New York: Free Press. 
Porter, Michael. 1996. What is strategy? Harvard Business Review 74: 61-78.

Prahalad, Coimbatore K., and Richard A. Bettis. 1986. The dominant logic: a new linkage between diversity and performance. Strategic Management Journal 7(6): 485-501.

Richter, Ansgar, and Sascha L. Schmidt. 2005. How does strategy process influence strategy content? Antecedents of consistency between resource allocation decisions and corporate strategy. Schmalenbach Business Review 57(4): 332-350.

Rhodes-Kropf, Matthew, David T. Robinson, and S. Viswanathan. 2005. Valuation waves and merger activity: the empirical evidence. Journal of Financial Economics 77(3): 561-603.

Robins, James A., and Margarethe F. Wiersema. 2003. The measurement of corporate portfolio strategy: analysis of the content validity of related diversification indexes. Strategic Management Journal 24(1): 39-59.

Robinson Jr, Richard B., and John A. Pearce II. 1988. Planned patterns of strategic behavior and their relationship to business-unit performance. Strategic Management Journal 9(1): 43-60.

Rossi, Stefano, and Paolo F. Volpin. 2004. Cross-country determinants of mergers and acquisitions. Journal of Financial Economics 74(2): 277-304.

Rumelt, Richard. 1980. The evaluation of business strategy. In Strategic management and business policy, ed. W.F. Glueck, 359-367. New York: McGraw-Hill.

Seth, Anju. 1990. Sources of value creation in acquisitions: an empirical investigation. Strategic Management Journal 11(6): 431-446.

Shi, Weilei, and John E. Prescott. 2011. Sequence patterns of firms' acquisition and alliance behaviour and their performance implications. Journal of Management Studies 48(5): 1044-1070.

Shi, Weilei, and John E. Prescott. 2012. Rhythm and entrainment of acquisition and alliance initiatives and firm performance: a temporal perspective. Organization Studies 33(10): 1281-1310.

Shi, Weilei, Jing Sun, and John E. Prescott. 2012. A temporal perspective of merger and acquisition and strategic alliance initiatives: review and future direction. Journal of Management 38(1): 164-209.

Shrivastava, Paul. 1986. Postmerger integration. Journal of Business Strategy 7(1): 65-76.

Siggelkow, Nicolaj. 2002. Evolution toward fit. Administrative Science Quarterly 47(1): 125-159.

Thorndike, Edward L., and Robert S. Woodworth. 1901. The influence of improvement in one mental function upon the efficiency of other functions. Psychological Review 8(3): 247-261.

Travlos, Nickolaos. 1987. Corporate takeover bids, methods of payment, and bidding firms' stock returns. The Journal of Finance 42(4): 943-963.

Uhlenbruck, Klaus, Michael A. Hitt, and Matthew Semadeni. 2006. Market value effects of acquisitions involving internet firms: A resource-based analysis. Strategic Management Journal 27(10): 899-913.

Vermeulen, Freek, and Harry G. Barkema. 2001. Learning through acquisitions. Academy of Management Journal 44(3): 457-476.

Walsh, James. 1995. Managerial and Organizational Cognition: notes from a Trip Down Memory Lane. Organization Science 6(3): 280-321.

Walsh, Janmes, and Gerardo Rivera Ungson. 1991. Organzational Memory. The Academy of Management Review 16(1): 57-91.

Weick, Karl E., and David P. Gilfillan. 1971. Fate of arbitrary traditions in a laboratory microculture. Journal of Personality and Social Psychology 17: 179-191.

White, Halbert. 1980. A heteroskedasticity-consistent covariance matrix estimator and a direct test for heteroskedasticity. Econometrica 48(4): 817-838.

White, J. Dennis, and Donald E. Carlston. 1983. Consequences of schemata for attention, impressions, and recall in complex social interactions. Journal of Personality and Social Psychology 45: 538-549.

Yelle, Louis. 1979. The learning curve: historical review and comprehensive survey. Decision Sciences 10(2): 302-328.

Zollo, Maurizio, Jeffrey J. Reuer, and Harbir Singh. 2002. Interorganizational Routines and Performance in Strategic Alliances. Organization Science 13(6): 701-713.

Zollo, Maurizio, and Harbir Singh. 2004. Deliberate Learning in Corporate Acquisitions: PostAcquisition Strategies and Integration Capability in US Bank Mergers. Strategic Management Journal 25(13): 1233-1256.

Zollo, Maurizio, and Degenhard Meier. 2008. What is M\&A performance? Academy of Management Perspectives 22(3): 55-77.

Zollo, Maurizio. 2009. Superstitious learning with rare strategic decisions: Theory and evidence from corporate acquisitions. Organization Science 20(5): 894-908. 